\title{
FEATURES OF TRANSITION MODES OF FRICTION SURFACES WITH PARTIALLY REGULAR MICRORELIEF
}

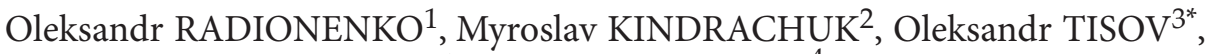 \\ Andrii KRYZHANOVSKYI ${ }^{4}$ \\ ${ }^{1}$ Pryazovskyi State Technical University, Mariupol, Ukraine \\ 2, 3,4 National Aviation University, Kyiv, Ukraine
}

Received 03 October 2017; accepted 24 June 2018

\begin{abstract}
Textured surfaces with partially regular micro relief (PRMR) are reported to be an effective means to control lublication. It was found they are good wear debris trap and suppliers of lubricant directly to the actual friction area. Their tribological properties depend on the clearance between mating surfaces, relative slip speed, direction of motion. These parameters change the lubrication regime, and vice versa changing geometry of PRMR it is possible to predict and control lubrication regime for given conditions. Application of micro textured surface is prospective for high precision sliding units - valve slides of oil and hydraulic systems, faces of gear pump gears, ring-to-cylinder interface of aircraft reciprocating engines etc. providing high service life. On other side, changing texture parameters it is possible to stop the leakage of fluid through the gap, what may be efficiently utilized in aircraft non-contacting mechanical (hydrodynamic and hydrostatic) seals of gas compressors and gear mechanisms. This paper discloses some peculiarities of transition lubrication regimes for textured surfaces in lubricated contact.
\end{abstract}

Keywords: partially regular micro relief, lubrication regime, friction coefficient, rate of temperature change, hysteresis, precision aircraft equipment, oil pump.

\section{Introduction}

Increasing and continuing service life of engineering products, improving their reliability is an urgent engineering problem and a particular issue for aircraft.

To improve wear resistance of friction surfaces a number of methods are now applied or under development. One of the ways to increase wear resistance of friction surfaces is surface texturing (Ibatan, Uddin, \& Chowdhury, 2015).

Recently, the studies of textured surfaces develop quite excessively. On friction surfaces micro impressions may be formed by selective laser treatment (Saeidi, Meylan, Hoffmann, \& Wasmer, 2016; Bolutife, Cinta, Oyelayo, \& Ezekiel, 2015; Guo, 2009; Okamoto, Jibiki, Ito, \& Motoda, 2016; Wu, Chen, Fan, \& Liu, 2016; Lu, Wood, Gee, Wang, \& Pfleging, 2016).

Micro impressions also may be formed by mechanical treatment (Pettersson \& Jacobson, 2006, 2007; Hakan \& Sofuoglu, 2013).

Many researches have being studied the effect of area ratio, positioning, depth and shape of micro impressions on friction couple tribology (Galda, Koszela, \& Pawlus,
2007; Wos, Koszela, \& Pawlus, 2017; Cong \& Khonsari, 2016; Sihuan, Yuan, Huang, \& Wang, 2011; Hao, Meng, \& Chen, 2014).

Many papers are devoted to the study of friction processes of surfaces with micro grooves formed by surface plastic deformation (Kindrachuk, Radionenko, Kryzhanovskyi, \& Marchuk, 2014; Pashechko, Kindrachuk, \& Radionenko, 2016; Baranov, Dronov, Lavrukhyn, \& Tretiakov, 2016; Chernyshev, Shatokhyn, \& Khaibullyn, 2010; Golubchikov \& Kuzmin, 2010; Morgunov, Pogodaev, \& Masyagin, 2004; Shneyder, 1982). These surfaces are called surfaces with partially regular microrelief.

The practical application of textured surfaces (or surfaces with micro grooves) in friction couples has some restrictions and limitations. In this work, we have studied the lubrication regimes of surfaces with micro grooves in order to analyze friction mechanism, to determine their possible drawbacks and to evaluate their application in aerospace engineering.

Surfaces with PRMR are surfaces on which microimpressions or microgrooves are formed by various techno-

${ }^{*}$ Corresponding author. E-mail: tissov@ukr.net 
logical methods (Radionenko, 1988). One of the methods for obtaining surfaces with PRMR is vibro-rolling - the formation on the friction surface of a grid of microgrooves with the help of a spherical indenter by the method of surface plastic deformation (Figure 1).

Hitherto many studies of friction of surfaces with PRMR have been made. They report positive impact of PRMR on arising of mixed or hydrodynamic lubrication. However, surfaces with PRMR haven't found wide application in contrast to products treated by conventional methods - grinding, super-finishing, honing etc. In part, this is due to the fact that vibro-rolling leads to metal outflows along the edges of the micro-grooves (Figure 2), which, if not removed, lead to increased wear of friction surfaces. In addition, in some cases, an increase in the friction coefficient at boundary friction and an increased consumption of lubricating oil are observed. The industrial application of surfaces with PRMR is inhibited also as a result of the fact that they are more sensitive to the amount of lubricant supplied to the friction zone than surfaces without microgrooves, and the optimization of the parameters of PRMR depends on the lubrication regime - boundary, mixed or hydrodynamic. Previously conducted research work was carried out on friction couples, not devoid of errors of shape in the form of ovality, facetting, deviation from cylindricity or location errors, such as deviation from parallelity of the specimen and counterpart axis. All these errors lead to the appearance of additional gaps between the frictional surfaces in which the lubricating oil is located and can distort the lubrication effect of the microgrooves PRMR.

Chahge of desired lubrication regime to the other one during operation is unwanted. This may be constantly monitored during experimental studies by continuous measuring or electrical resistance and temperature be-

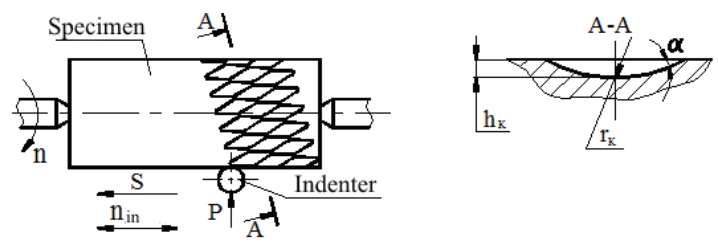

Figure 1. Forming micro grooves on cylindrical surface

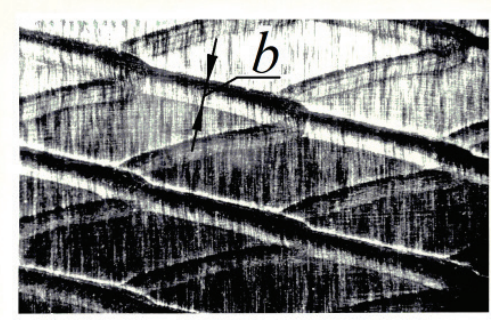

Figure 2. Top view of micro grooves - metal outflows on the edges, $b=0.5 \mathrm{~mm}$ tween mating surfaces. Change of lubrication regime causes the deviation of resistance oscillogram and the rate of temperature change. Change of lubrication regime is an evidence of system mulfunctioning. During aircraft maintenace, possibility to monitor these parameters may be used for automated aircraft inspection systems. In most friction couples wear occurs at boundary lubrication regime, so when studying lubricated wear couple it is necessary to clearly detect boundary regime. It is therefore necessary to develop methods to control lubrication regimes.

\section{Experimental procedures and test rig}

Monitoring the lubrication regime and the thickness of the lubricating film in friction zone is the most difficult task in tribological studies. The separation of the lubrication regime into boundary, mixedand hydrodynamic lubrication in experimental studies is possible on the basis of the Stribeck curve; By the thickness of the lubricating film; By the nature of the oscillograms obtained by measuring the electrical resistivity of the lubricating film; By the friction coefficient.

The Stribeck curve shows the dependence of the friction coefficient $\mathrm{f}$ on the Sommerfeld criterion, which includes the viscosity of the lubricating oil, the slip velocity $V$, and the pressure $P$ (Figure 3 ). This curve can be obtained by changing one of the parameters of the Sommerfeld criterion.

To the left of the point $a$ there is a region of friction without lubricant. It was assumed that to the left of the point $a$ there is also a boundary lubrication region. This method of controlling the friction regime is very approximate, because the position of points $a, b$ and $c$ is uncertain, especially of point $a$, which makes it difficult to isolate the friction region with boundary lubrication.

Determination of the friction regime by the nature of the oscillograms is possible when the electrical resistivity of the lubricating film is monitored. In this case, an electronic oscilloscope is connected to the electric circuit in parallel to the generator of the sinusoidal signal and the resistance of the lubricating film is to be measured. With boundary friction, a straight line is observed on the oscilloscope screen, while in the case of a hydrodynamic friction a sinusoidal line is observed. In transient modes

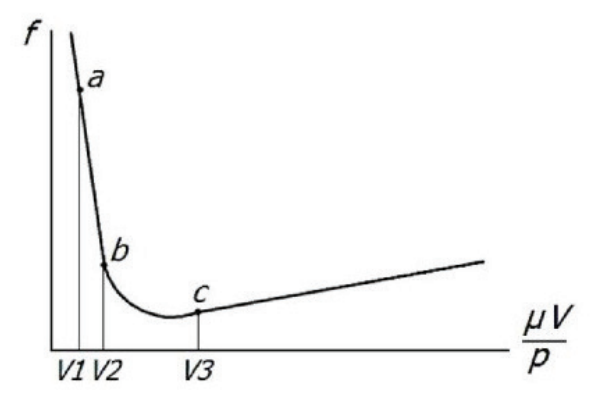

Figure 3. Fields of friction regimes on Stribeck curve due to change of slip velocity $V$ 
from boundary to hydrodynamic, flickering sinusoids and straight lines are observed.

The determination of the friction mode by the value of the friction coefficient is the least accurate. The following values of the friction coefficients were assumed: hydrodynamic lubrication $-f=0.005$, boundary lubrication $-f=0.02 \ldots 0.1$. For boundary lubrication $f=0.1$ ... 0.4, the boundary regime of hydrodynamic friction $f=$ $0.008 \ldots 0.02$. Bowden and Tabor believe that the boundary lubrication is characterized by a change in the friction coefficient in the range $0.05 \ldots 0.1$.

To control the friction mode and to measure electrical resistance of the lubricating film, a method using a bridge circuit was used, which is used for more accurate measurements than measuring the resistance by a voltage drop across it.

To avoid breakdown of the lubricating film, the voltage applied to it did not exceed $30 \mathrm{mV}$. The frequency of the signal was $5 \mathrm{kHz}$, which also reduced the probability of breakdown due to the exclusion of the polarization of the lubricant and allowed to retain the lubricating properties of the oil.

The friction regime was monitored by means of electronic oscilloscope $10(\mathrm{C1}-76)$, which was connected directly to the amplifier 8 (Y4-28), which allowed observing on the oscilloscope screen typical oscillograms for boundary, mixed and hydrodynamic friction regimes. The values of friction moment, trmperature rpm's were determined using oscillograph $H 115$.

When developing means to control lubrication regime and lubricating film thickness we made special demands to maximum amplitude of oscillations and reliability of parameters being registered. To meet this demand a special mercury current collector was manufactured (Figure 4).

The manufactured mercury single-groove current collector makes it possible to measure the resistance in sliding friction units with a horizontal axis of rotation (Figure 3) for a long time, provides reliable protection against the escape of mercury vapor and the stability of the transient resistance (Radionenko, 1987). The oscillations of the transient resistance when working with a horizontally located shaft from which the signal was taken off did not exceed $10^{-3} \mathrm{Ohm}$. The shaft rotation frequency reached $33 \mathrm{sec}^{-1}$.

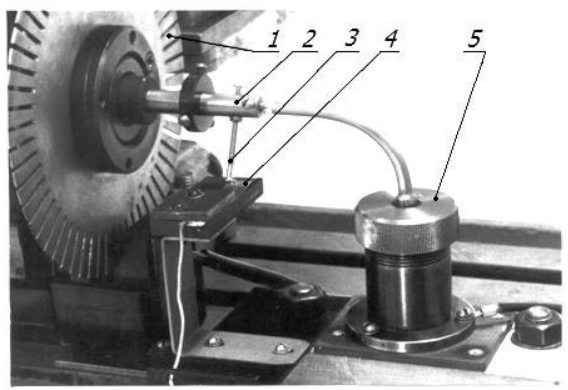

Figure 4. Revolutions counter and current collector: 1 - tachometer light interrupter; 2 - shank of the leading center; 3 and 4 - rotary and stationary contacts of the revolutions counter; 5 - current collector
In this work, we studied conditions of different lubrication regimes occurrence: boundary, hydrodynamic and mixed. The study was carried out using precision tribometer (Figure 5). Test layout - steel tape (stationary) over shaft (rotating) (Figures 6 and 7) (Kragelskiy, Dobyichin, \& Kombalov, 1977).

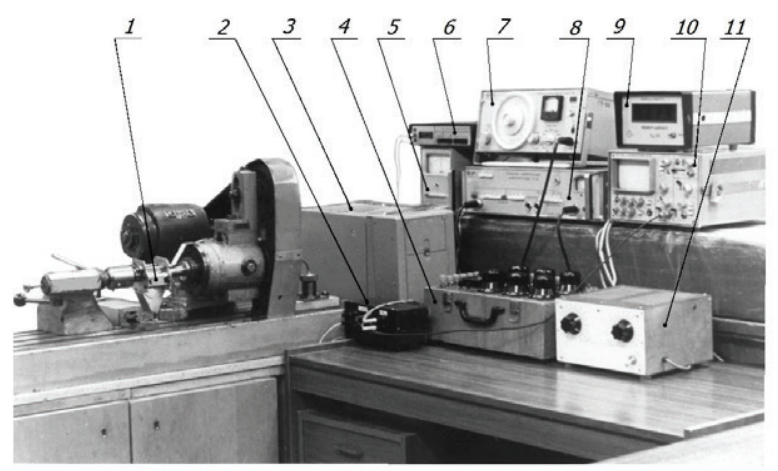

Figure 5. Test rig for tribological investigations: 1 - tribometer; 2 - block with isolating transformer, half bridge of resistances and diode bridge; 3 - light-beam oscillograph $\mathrm{H}$ 115; 4 - resistance control set; 5 - the electronic block of the inductive sensor; 6 - millivoltmeter; 7 - signal generator GZ-102; 8 - measuring amplifier Y4-28; 9 - digital tachometer TC-ZM; 10 - oscilloscope C1-76;

11 - control unit for electric drive of tribometer

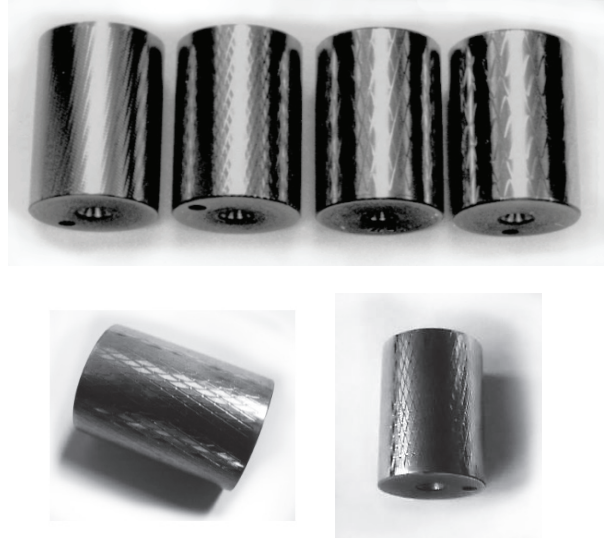

Figure 6. Textured specimens with various relative area of microgrooves $F_{\kappa}$

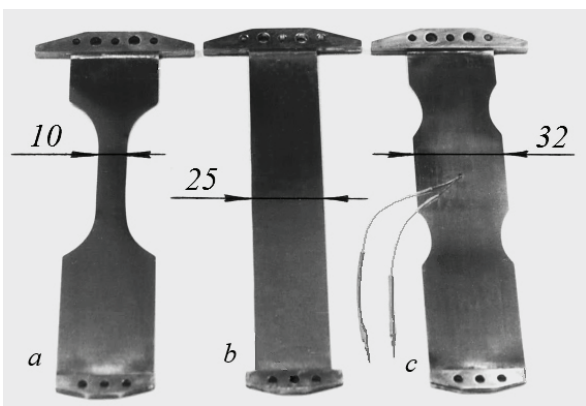

Figure 7. Counterparts: $\mathrm{a}, \mathrm{b}$ - for boundary lubrication; c - hydrodynamic lubrication (thermocouple fixed to the surface). Dimensions in milimiters 
The application of test layout - tape-over-shaft made it possible to exclude the macroprocessing and avoid gaps in the friction couple due to errors in shape and position (Figure 8).

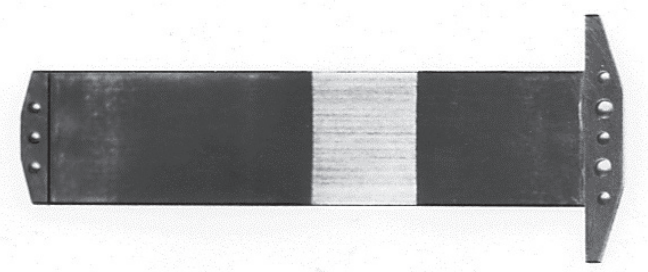

Figure 8. Counterpart after test with smooth shaft specimen

High accuracy of measuring the friction coefficient was also provided by using a highly sensitive vibration sensor of the tribometer carriage and using a transmission lever.

In the experiments, grinded and adjusted to $R_{a}=0.1$ $\mu m$ and with a tolerance of $0.005 \mathrm{~mm}$ diameter specimens were used. Specimed diameter $d=30 \mathrm{~mm}$ made of carbon steel 1045, hardness HRC 30...32. Some of the samples were subjected to vibro-rolling with different processing regimes to obtain samples with different parameters of the PRMR. The angle of the grid of microgrooves did not change. Vibration rolled samples were brought to a fine-grained sandpaper on a rigid liner in order to remove the outflows along the edges of the microgrooves formed during the SPD treatment. After microprocessing of the samples in pair with the tape, the roughness of the working surfaces was $R_{a}=0.15 \mu \mathrm{m}$. The error in the shape of the samples is not more than $3 \mu \mathrm{m}$. When working on test layout - tape-over-shaft, a steel tape with a width of $32 \mathrm{~mm}$ and a thickness of $0.06 \mathrm{~mm}$ made of carbon steel $\mathrm{U} 8$ ( $0.8 \%$ of carbon) was used as a counterpart.

All experiments were performed with Industrial-20 lubricating oil with continuous feeding of oil into the friction zone. The loading force of the sample in all the experiments was $0.47 \mathrm{kN}$, the nominal pressure was $0.61 \mathrm{MPa}$. The temperature was controlled during the friction process with the aid of a chromel-kopel thermocouple, the working junction of which was soldered onto the strip of the counterpart. Thus, the working junction was at a distance of $0.06 \mathrm{~mm}$ from the friction zone.

The measurement of the frictional moment, sliding velocity, and temperature was carried out according to the procedure described in (Kindrachuk et al., 2014). The friction coefficients were calculated by the formula given in (Kindrachuk et al., 2014).

\section{Results and discussion}

The results of studies of specimens with a depth of microgrooves $h=7 \mu \mathrm{m}$ and a radius of the bottom of the groove $r=1 \mathrm{~mm}$ with continuous lubrication are shown in Figure 9.

The dependence of the friction coefficient $f$ on the slip velocity $V$ has a characteristic form of Stribeck curve.

By measuring the rate of temperature change $\Delta T / \Delta t$ ( $\Delta T$ - temperature difference, $\Delta t-$ time) it becomes possible to determine the area of boundary lubrication. This is a range of low speeds in the initial section of Stribeck curve. Here, increment of sliding speed $V$ causes the increase of the
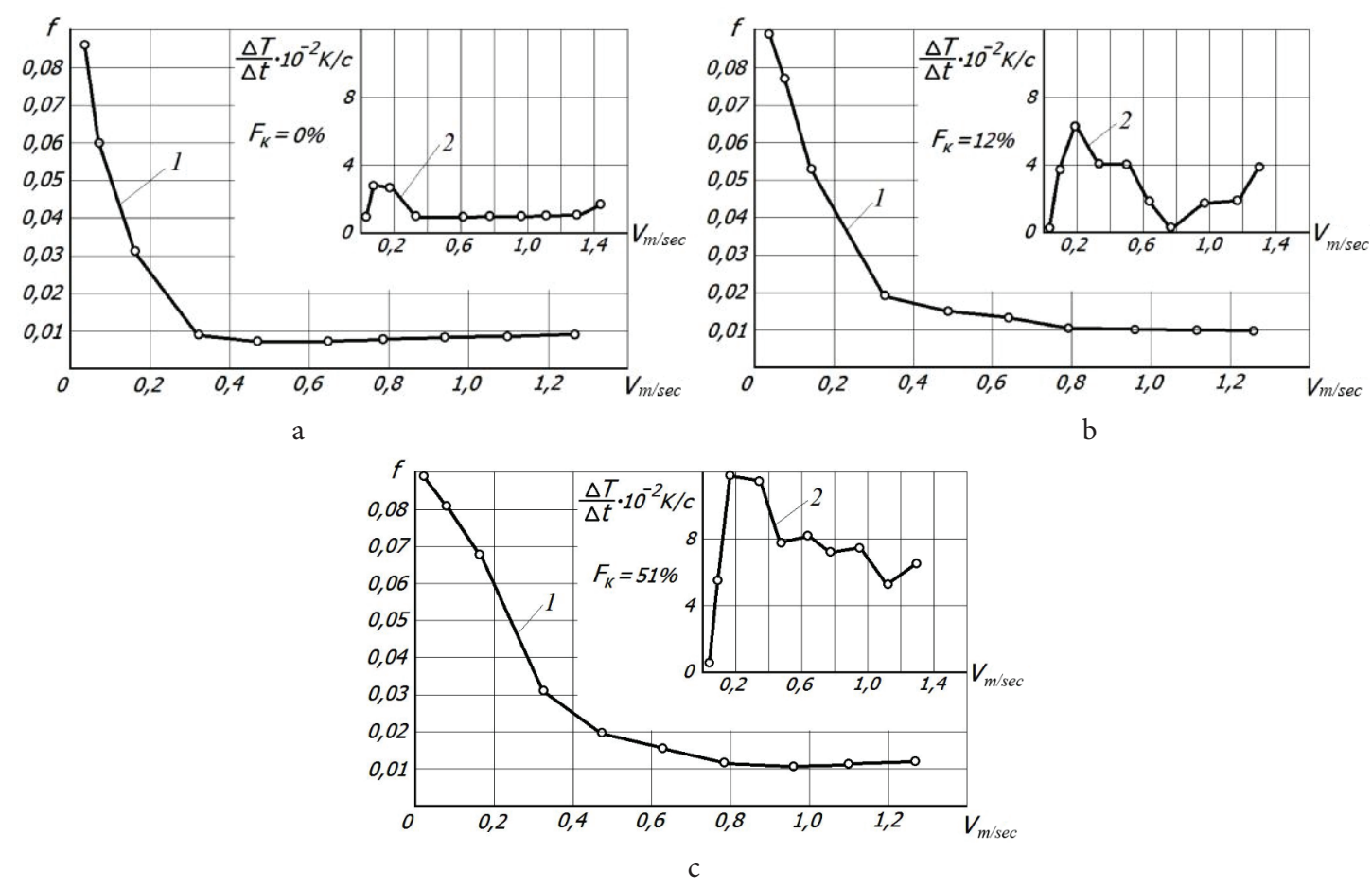

Figure 9. The dependence of friction coefficient $f(1)$ and rate of temperature change $T / \Delta t(2)$ sersus slip velocity $V$ at relative area of microgrooves $F_{\kappa}: a-F_{\kappa}=0 \% ; \sigma-F_{\kappa}=12 \% ; \beta-F_{\kappa}=51 \%$ 
rate of temperature change $\Delta T / \Delta t$ (section $A$ in Figure 10). It is clearly seen that friction coefficient rapidly decreases. According to Stribeck diagram, this corresponds to transition from boundary lubrication regime (monomolecular lubricating film) to mixed lubrication regime. At the same time, the rate of temperature change rapidly increases. This is explained by dissimilar contribution of deformation and adhesion on heat generated in contact area.

On section $A$ with increasing of sliding speed $\mathrm{V}$ the thickness of lubricating film also increases. This leads to decrease of contribution of adhesion on heat generation, but increases the contribution of deformation (due to deformation of metal outflows on the edges of microgrooves, Figure 2). The contribution of deformation to heat generation, evidently, is much higher. This causes the rise of $\Delta T /$ $\Delta t$. With further increase of $V$ the thickness of lubricating film increases even much more, and the contribution of deformation on heat generation decreases.

Boundary lubrication in this speed range was confirmed and the nature of the oscillograms - a straight, slightly flickering line is visible. With increasing speed $V$ and approaching section $B$ (Figure 10), weak splashes of the sinusoid appear on the screen (Figure 11, a).

It should be noted that in the region of boundary lubrication, the friction coefficient sharply decreases with increasing velocity $V$, and the rate of increase in temperature $T / \Delta t$ increases. The decrease in the friction coefficient $f$ with increasing $V$ is explained by increase in thickness of lubricating film, starting from a monolayer to several layers. The examination of lubrication regime using the rate of temperature change $\Delta \mathrm{T} / \Delta \mathrm{t}$ was not used before. This work - is an attempt to use a new method to do this. This method is in good agreement with the method of determining lubrication regime using resistance oscillograms and may be explained be adhesion-deformation theory of friction

The rate of temperature change $\Delta \mathrm{T} / \Delta \mathrm{t}$ is affected by the number of asperities being in contact with edges of microgrooves of PRMR (or by contact of counter-parting asperities of sample and counterpart if both have no PRMR). The higher the sliding velocity $V$ or the greater $F$, the greater the number of adhesive weld joints formed per unit time, the more is the energy of interaction of asperities with the edges of microgrooves. This will cause greater amount of heat produced per unit time.

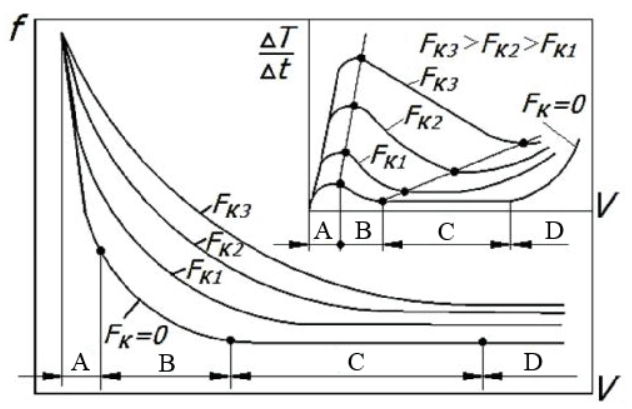

Figure 10. Borders of friction regimes depending on relative area of microgrooves $F_{\kappa}$ and slip velocity $V$
From the graphs in Figure 9 it is clear that, at the boundary lubrication, the growth rate of temperature change rises as $F_{c}$ increases. In our opinion, there is an increase in the deformation component of the friction coefficient with increasing $F_{k}$, even with a small roughness of the counterparts. A decrease in the friction coefficient $f$ and the rate of temperature change $T / \Delta t$ is observed in section $B$ (Figure 10), which is associated with a further increase in the thickness of the lubricating film, and in turn leads to a decrease in the number of contacts per unit time of microprotrusions of the counterpart with microgroove edges (Pashechko et al., 2016). On the oscillograms there are flickering sinusoids, which indicate a mixed lubrication mode (Figure 11, b).

With a further increase in sliding velocity $V$, the thickness of the lubricating film should increase, but with increasing $F_{k}$ it decreases. The actual decrease in the film thickness with increasing $F_{k}$ and $V$ is caused by the beginning of drainage of the lubricating oil from the friction zone along the microgrooves.

Section $C$ is characteristic for friction of surfaces without PRMR $\left(F_{k}=0\right)$. In this range of friction rates, the rate of temperature change $\Delta T / \Delta t$ remains constant, i.e. despite the increase in the velocity $V$, the amount of heat produced per unit time does not change. The reason for this fact is, apparently, a decrease in the number of actual microroughness contacts per unit time due to the growth of the film thickness with a proportional increase in the energy of the interaction between the microroughnesses and the energy of formation and rupture of adhesive welding bridges with increasing velocity $V$.

The growth of the thickness of the lubricating film at $F_{k}=0$ is confirmed by graphs (Figure 9). Oscillograms with friction in the diapason $C$ have the form more close to the hydrodynamic regime, but a metallic contact between the friction surfaces is present, as evidenced by weak measuring lines and a blurred image of the sinusoid on the oscilloscope screen.

In the section $D$, with a change in the sliding velocity, the value of $T / \Delta t$ is smoothly increased with an al-

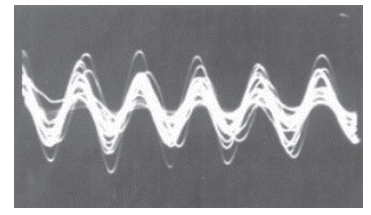

a

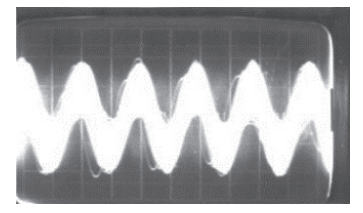

b

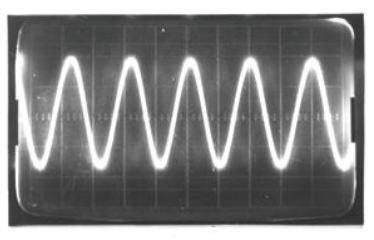

C

Figure 11. Oscillograms of the friction modes: a - transition mode from boundary to mixed lubrication; $\mathrm{b}$ - transition mode from mixed to hydrodynamic lubrication; $\mathrm{c}$ - hydrodynamic lubrication 
most constant friction coefficient (Figure 9). The increase in the thickness of the lubricating film in this range of speeds is slowed down. The main reason for the slowdown in the growth of the thickness of the lubricating film is the intensive drainage of oil through microgrooves outside the friction surfaces. As a result of oil drainage, the hydrodynamic regime did not form, but remained mixed, but more unstable than in sections $B$ and $C$. Only a few bursts of $R_{X}$ up to $900 \mathrm{Ohm}$ were observed, and for the instants of the oscillogram took the form characteristic for hydrodynamic friction (Figure $7, \mathrm{c}$ ). The growth of $T /$ $\Delta t$ in the section $D$ is due to high friction rates with a negligible thickness of the lubricating film. The increase in the hydrodynamic pressure was indicated by the fact that the flexible steel band (the counterpart) slightly bent in the center of the contact zone.

\subsection{Hysteresis effect}

Hysteresis in tribotechnical systems is a physical phenomenon, which is explained by irreversible changes, caused by dissimilar run of direct and inverse processes.

In investigating the friction regimes of surfaces with a partially regular microrelief, the hysteresis effect was observed for the friction coefficient with a change in the slip velocity vector.

The rotation speed of specimen $n$ was controlled by a digital tachometer and could smoothly vary from 20 to $2000 \mathrm{rpm}(\mathrm{V}=3.14 \times 10-2-3.14 \mathrm{~m} / \mathrm{sec})$.

Curves obtained (Figure 8) are similar to the Hersey diagram and sections $B$ and $C$ in Figure 6. The graphs in Figure 8 correspond to transition regimes from boundary to mixed lubrication and from mixed to hydrodynamic lubrication.

With a smooth increase in the slip velocity $V$, the graphs of the friction coefficient $f$ versus $V$ differ from the graphs with a smooth decrease in the slip velocity $V$ (Figure 8). The friction coefficient sharply decreases to a minimum with increasing rotational speed of sample $n$, and furthurer it is insignificant and gradually increases. It is an interesting part of the curve (Figure 6), where the friction coefficient corresponds to the minimum value, is, according to the Stribeck diagram, mixed lubrication and the beginning of a hydrodynamic friction.

In this section, the hysteresis of the friction coefficient is found, i.e. with a smooth increase in the speed $n$ up to $900 \mathrm{rpm}$ and then, reducing to the same intermediate values of $n$, a hysteresis loop was formed. As the relative area of the microgrooves $F_{k}$ increases, the friction coefficient increases with the same values of $n$, and the hysteresis loop moves up and to the right, i.e. mixed lubrication arose at large rotational frequencies of specimen $n$ and large friction coefficients. In addition, the difference in the values of $f$ for the same $n$ decreased, i. e. the hysteresis loop narrowed. The minimum value of $f$ was obtained on specimens without microgrooves, i.e. when $F_{k}=0$.

When analyzing the dependencies (Figure 8). it can be seen that the friction coefficients for a smooth increase in the slip velocity $V$ are smaller than the friction coefficients obtained with a smooth decrease in the velocity $V$ and less than the coefficients for the steady-state friction regime when $n$ was fixed $(\Delta V=0)$.

Graphs 1 in Figure 12 were obtained during a separate experiment with the stabilization of the lubrication regime, which occurred at a constant slip velocity $V$ for $10 \ldots 30 \mathrm{sec}$.

The friction coefficients are most different for cases $1,2,3$ at $F_{k}=0$, i.e. for surfaces without microgrooves.

For large $F_{k}$ the friction coefficients are higher and the region of the minimum shifts toward an increase of $V$.

A reliable explanation for the tribotechnical effect of the hysteresis of the friction coefficient at this stage of the study has not yet been found. It can be assumed that the hysteresis of the friction coefficient for mixed lubrication and in the initial section of hydrodynamic friction is due to the gradient of the feed rate of the lubricant into the entrance zone of the radial sliding bearing. The increase in the friction coefficients with increasing $F_{k}$ and the narrowing of the hysteresis loop can be explained by the increased end drainage of the lubricating oil due to the microframes of the PRMR

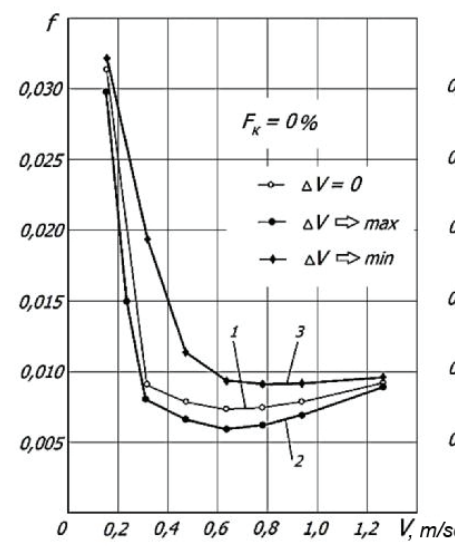

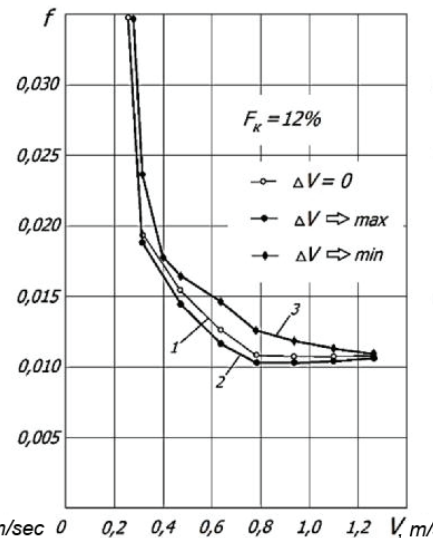

b

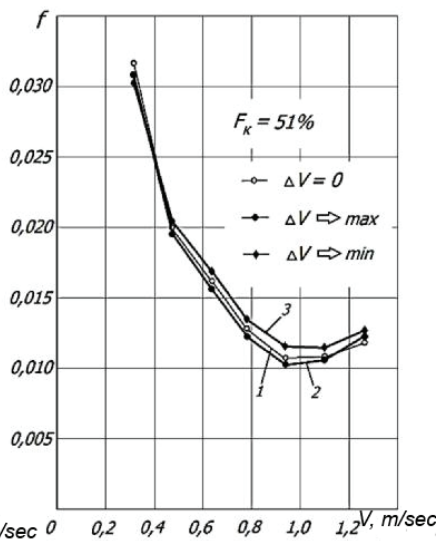

C

Figure 12. Dependence of the friction coefficient $f$ on the velocity $V: 1-$ under the steady-state friction regime $(\Delta V=0) ; 2$ - with a smooth increase in the sliding velocity $V ; 3$ - with a smooth decrease in the speed $V$. T he relative area of microgrooves $F_{k}: A-F_{k}=0 \% ; B-F_{k}=12 \% ; B-F_{k}=51 \%$ 


\section{Conclusions}

Based on results of analyses and examinations, the following conclusions (about friction mechanism of textured PRMR surfaces, their drawbacks and possibility to be used in aerospace engineering) may be drawn:

1. Developed method of studying friction process of surfaces with PRMR allows to control lubrication regimes. Among known methods of determining the lubrication regime the method of measuring the electrical resistance of lubricating film and analyzing the shape of oscillograms is the most acceptable. Another reliable method to register lubrication regime is measuring the rate of temperature change $\Delta \mathrm{T} / \Delta \mathrm{t}$ in friction zone with increasing sliding speed.

2. For boundary lubrication the rate of temperature change $\Delta \mathrm{T} / \Delta \mathrm{t}$ with increasing sliding speed $V$ is growing, and simultaneously friction coefficient reduces.

3. Friction surface with microgrooves (PRMR) significantly increases the drainage of lubricating oil from friction zone with increasing of sliding speed $V$ or increasing of relative area of microgrooves $F_{k}$.

4. Friction surfaces with PRMR have significant effect on deformation component of friction factor. This is caused by contact of microgrooves edges with asperities of contiguous surface.

5. The hysteresis of friction coefficient under mixed lubrication and in initial period of hydrodynamic lubrication is caused by increasing lubricant supply into the inlet of radial sliding bearing. The increase in friction with increasing $F_{k}$ and narrowing of the hysteresis loop may be attributed to the increased drainage of the lubricating oil through the grooves of PRMR.

\section{References}

Baranov, V. L., Dronov, E. A., Lavrukhyn, V. N., \& Tretiakov, N. V. (2016). Fynyshnaia obrabotka vnutrennei poverkhnosty tsylyndrov dvyhatelei vnutrenneho shoranyia. In Yzvestyia Tulskoho hosudarstvennoho unyversyteta (pp. 15-19). Tekhnycheskye nauky.

Bolutife, O., Cinta, L. M., Oyelayo, O. A., \& Ezekiel, O. A. (2015). Effect of laser surface texturing (LST) on tribochemical films dynamics and friction and wear performance. Wear, 332-333, 1225-1230.

Chernyshev, V. P., Shatokhyn, B. C., \& Khaibullyn, P. P. (2010). Povyshenye dolhovechnosty hylz tsylyndrov DVS obrazovanyem rehuliarnoho mykrorelefa. In Trudyi GOSNITI / Vserosiiskaya nauchno-issledovatelskaya tehnologicheskaya institutt remonta i ekspluatatsii mashynno-traktornogo parka (Vol. 105, pp. 91-94). Moskva.

Cong, S., \& Khonsari, M. M. (2016). Texture shape optimization for seal-like parallel surfaces: theory and experiment. Journal Tribology Transactions, 59(4), 698-706. https://doi.org/10.1080/10402004.2015.1110220

Galda, L., Koszela, W., \& Pawlus, P. (2007). Surface geometry of slide bearings after percussive burnishing. Tribology International, 40, (10-12), 1516-1525. https://doi.org/10.1016/j.triboint.2007.01.010

Golubchikov, M. A., \& Kuzmin, Y. P. (2010). Modelirovanie protsessa vibronakatyivaniya. Izvestiya vuzov. Priborostroenie, 53(8), 26-29.

Guo, K. W. (2009). Effect of sliding speed on tribological characteristics of different surface textures on AISI O1 steel irradiated by Nd: YAG pulsed laser. Ironmaking \& Steelmaking, 36, 63-74. https://doi.org/10.1179/174328108X335131
Hakan, A., \& Sofuoglu, H. (2013). An investigation of tribological behaviors of dynamically loaded non-grooved and microgrooved journal bearings. Tribology International, 58, 12-19. https://doi.org/10.1016/j.triboint.2012.09.009

Hao, L., Meng, Y., \& Chen, C. (2014). Experimental investigation on effects of surface texturing on lubrication of initial line contacts. Lubrication Science, 26(5), 363-373. https://doi.org/10.1002/ls.1265

Ibatan, T., Uddin, M. S., \& Chowdhury, M. A. K. (2015). Recent development on surface texturing in enhancing tribological performance of bearing sliders. Surface and Coatings Technology, 272, 102-120. https://doi.org/10.1016/j.surfcoat.2015.04.017

Kragelskiy, I. V., Dobyichin, M. P., \& Kombalov, V. S. (1977). Osnovyi raschetov na trenie i iznos. M.: Mashinostroenie.

Kindrachuk, M., Radionenko, O., Kryzhanovskyi, A., \& Marchuk, V. (2014). The friction mechanism between surfaces with regular microgrooves under boundary lubrication. Aviation, 18(2), 64-71. https://doi.org/10.3846/16487788.2014.926642

Lu, P., Wood, R. J. K., Gee, M. G., Wang, L., \& Pfleging, W. (2016). The friction reducing effect of square-shaped surface textures under lubricated line-contacts - an experimental study. Lubricants, 4(3), 26. https://doi.org/10.3390/lubricants4030026

Morgunov, A. P., Pogodaev, V. P., \& Masyagin, V. B. (2004). Otnositelnaya ploschad poverhnosti chastichno regulyarnogo mikrorelefa pri obkatyivanii vraschayuschimsya instrumentom. In Novyie materialyi i tehnologii: Tezisyi vserossiyskoy nauchno-tehnicheskoi konferencyi (pp. 34-36). Rubtsovsk: RII.

Okamoto, M., Jibiki, T., Ito, S., \& Motoda, T. (2016). Role of cross-grooved type texturing in acceleration of initial running-in under lubricated fretting. Tribology International, 100, 126-131. https://doi.org/10.1016/j.triboint.2015.12.012

Pashechko, M., Kindrachuk, M., \& Radionenko, O. (2016). The mechanism of friction between surfaces with regular microgrooves under boundary lubrication. Advances in Science and Technology Research Journal, 10(32), 82-85. https://doi.org/10.12913/22998624/65137

Pettersson, U., \& Jacobson, S. (2006). Tribological texturing of steel surfaces with a novel diamond embossing tool technique. Tribology International, 39(7), 695-700. https://doi.org/10.1016/j.triboint.2005.06.004

Pettersson, U., \& Jacobson, S. (2007). Textured surfaces for improved lubrication at high pressure and low sliding speed of roller-piston in hydraulic motors. Tribology International, 40(2), 355-359. https://doi.org/10.1371/journal.pone.0152100

Radionenko, A. V. (1988). Tokos' emnik priborov pretsizionnogo kontrolya sostoyaniya smazochnoy plenki v uzlah treniya. Izmeritelnaya Tehnika, 12, 20-21.

Radionenko, A. V. (1987). Tribometr dlya issledovaniya vliyaniya kachestva poverhnostey na sostoyanie smazochnoy plenki. Mashinovedenie, 6, 93-97.

Saeidi, F., Meylan, B., Hoffmann, P., \& Wasmer, K. (2016). Effect of surface texturing on cast iron reciprocating against steel under starved lubrication conditions: a parametric study. Wear, 348-349, 17-26. https://doi.org/10.1016/j.wear.2015.10.020

Shneyder, Y. G. (1982). Ekspluatatsionnyie svoystva detaley s regulyarnyim mikrorelefom. L.: Mashinostroenie.

Wos, S., Koszela, W., \& Pawlus, P. (2017). The effect of both surfaces textured on improvement of tribological properties of sliding elements. Tribology International, 113, 182-188. https://doi.org/10.1016/j.triboint.2016.10.044

Wu, W., Chen, G., Fan, B., \& Liu, J. (2016). Effect of groove surface texture on tribological characteristics and energy consumption under high temperature friction. PLoS ONE, 11(4), e0152100. https://doi.org/10.1371/journal.pone.0152100

Yuan, S., Huang, W., \& Wang, X. (2011). Orientation effects of micro-grooves on sliding surfaces. Tribology International, 44(9), 1047-1054. https://doi.org/10.1016/j.triboint.2011.04.007 